International Journal of Biology, Pharmacy and Allied Seiences (IJBPAS) 'A Bridge Betuen Caboratory and Qnendo' Www.ijbpas.com

\title{
ASSESSMENT OF PERIODONTAL HEALTH IN SMOKERS AND SMOKELESS TOBACCO USERS - A RETROSPECTIVE STUDY
}

\section{AHMED HILAL SHERIFF $\mathrm{K}^{1}$, BALAJI GANESH $\mathrm{S}^{2^{*}}$ AND RAKSHAGAN $\mathrm{V}^{3}$}

1: Saveetha Dental College and Hospitals, Saveetha Institute of Medical and Technical Science, Saveetha University, Chennai 77

2: Senior Lecturer, Department of Periodontics, Saveetha Dental College and Hospitals, Saveetha Institute of Medical and Technical Science, Saveetha University, Chennai 77

3: Senior Lecturer, Department of Prosthodontics, Saveetha Dental College and Hospitals, Saveetha Institute of Medical and Technical Science, Saveetha University, Chennai 77

*Corresponding Author: E Mail: Dr. Balaji Ganesh S: $\underline{\text { balajiganeshs.sdc@saveetha.com }}$

Received 19 ${ }^{\text {th }}$ March 2021; Revised 25 ${ }^{\text {th }}$ April. 2021; Accepted $20^{\text {th }}$ May 2021; Available online $1^{\text {st }}$ Aug. 2021

https://doi.org/10.31032/IJBPAS/2021/10.8.1058

\begin{abstract}
One fourth of the indian population still consumes tobacco in one form or the other. There are clear gender variations in the usage of tobacco products. Incidence of tobacco use is higher in lower socioeconomic individuals. Poor periodontal health is one of the many consequences of tobacco habits. The aim of this study was to evaluate the prevalence of different types of periodontal diseases of the patients with tobacco smoking and chewing habits. This university setting study involved a sample size of 2,178 patients. Data was tabulated with parameters of age, sex, habit and various types of periodontal diseases. The data was imported into spss for statistical analysis, the data was analyzed using chi square test. The total sample size of this study was 2,178 patients with the use of tobacco habits among them $87.8 \%$ of the patients were male and $12.17 \%$ were females. Among three categories of habits which is smoking, smokeless tobacco and both smoking and smokeless tobacco habit; male had a higher rate with $66.21 \%, 15.89 \%$ and $5.74 \%$ respectively, females were commonly only involved in smokeless habits with a rate of $11.89 \%$ and both males and females were mostly affected with generalised chronic gingivitis with $43.71 \%$. Among the age groups the smoking as well as smokeless habit was common in all
\end{abstract}


age groups although it was highest among the age group of 21-30years with smoking habit being $20.66 \%$, smokeless tobacco habit being $8.22 \%$ and patients with both smokeless and smoking habit being $1.79 \%$, also the age group 21-30years were mostly affected with generalised chronic gingivitis $(22.77 \%)$ and the age group 51-60 years were mostly affected with generalised chronic periodontitis (8.91\%). With respect to association between periodontal diseases and habits, generalised chronic gingivitis was mostly seen in all three groups $(31.36 \%, 17.45 \% \& 2.53 \%)$ followed by generalised chronic periodontitis $(20.06 \%$, $4.41 \%, 1.70 \%$ ). Within the limit of the study, we can conclude that the tobacco use has direct effect on the periodontium as most commonly the patients were affected with generalised chronic gingivitis followed by generalised chronic periodontitis, with males mostly affected and among the age of 21-30yrs. There is a need for further longitudinal studies in a large number of populations to assess the relationship of smoking and smokeless tobacco consumption with periodontal disease.

\section{Keywords: Gingivitis; Periodontitis; Smoking, Smokeless Tobacco}

\section{INTRODUCTION}

It is a belief and a fact, tobacco consumption habits among the indian population have been reported to be decreasing, but statistics relating to the prevalence of tobacco use confirm that one fourth of the indian population still consume tobacco in one form or the other. The most commonly used smokeless and smoke forms of tobacco are khaini/hans and beedi, in india. Although there is an increase in the trend of usage of these tobacco products, with $42.4 \%$ of men and $14.2 \%$ of women [1]. There is state wide variation in the prevalence of tobacco consumption with Tamil Nadu (20\%) demonstrating considerably lesser prevalence compared to the national average (28.6\%) [2]. It's been suggested that the incidence of tobacco use is higher among people belonging to lower social economic status $[3,4]$.

Periodontal diseases refer to the disintegration of connective tissue that anchors the tooth and could result in tooth mortality. Poor periodontal health is one of the many adverse health consequences of tobacco use which did not receive enough emphasis, as it has a significant negative effect of periodontal disease on the quality of life of the affected [5]. It is this increased incidence of deteriorating periodontal health due to the tobacco use, the dentists should enquire about the tobacco use among their patients and motivating them to quit the habit [6]. Smoking can be associated with the incidence of gingivitis, periodontitis and epithelial malignancy in the oral cavity. Tobacco smoking is one of the major risk 
factors for periodontal diseases. Smoking increases the number and depth of periodontal pockets and attachment loss. Loss of tissue strength which is caused by harmful compounds in tobacco can increase gingival recession and changes in the oral mucosa [7]. The prevalence of moderate and severe periodontitis is higher in smokers than nonsmokers. Periodontitis is 2 to 20 times higher in smokers than nonsmokers $[\mathbf{8}, \mathbf{9}]$. Smoking can have effects on epithelial thickness [10]. Moreover epithelial changes comprising basal layer hyperplasia and mild dysplasia have been demonstrated in pharynx, larynx and tongue mucosa [11].

In southern India, the most popularly smoked tobacco is bidi, which is made of $0.15-0.25 \mathrm{~g}$ sun-dried flaked tobacco rolled into a conical shape in a dried rectangular piece of Temburni leaf (Diospyros melanoxylon) and a thread securing the roll [12]. Bidi smoking is also an important risk factor for oral cancer. Smokeless tobacco products contain areca nut, catechu and lime, which cause harm to oral tissues. Use of smokeless tobacco products has been linked with various oral manifestations, which is seen localised at the site of smokeless tobacco placement in the oral cavity. The manifestations include oral mucosal lesions, gingival recession, gingival inflammation and periodontal attachment loss [13-16]. Various studies have been conducted under our institution, like in vitro studies $[\mathbf{1 7 , 1 8}]$, surveys [19], clinical trials [20-27] and review [28-31]. We are focusing now on retrospective studies. The aim of this study was to evaluate the prevalence of different types of periodontal diseases of the patients with tobacco smoking and chewing habits.

\section{MATERIALS AND METHODS}

This was a retrospective study regarding periodontal status among patients with smoking and smokeless tobacco habits attending Saveetha Dental College and Hospitals from June 2019 to March 2020. The ethical approval for this study is obtained from the ethical committee(ethical approval

number SDC/SIHEC/2020/DIASDATA/0619-0320). The sample size of this study was found to be 2,178 patients, of which 1913 of them were males and 265 of the patents were females. Inclusion Criteria: Patients with smoking and smokeless tobacco habits, males and females patients above the age of 18 . Exclusion Criteria: Presence of systemic diseases such as diabetes mellitus, cardiovascular diseases, history of periodontal treatment. The data was extracted and tabulated in the Microsoft Excel based on the parameters required. Once the case details have been obtained, the 
data was then extracted and tabulated based on the parameters which are age, gender, habits, periodontal health.

\section{Statistical analysis:}

Once the results have been tabulated based on the parameters, the data was then exported to SPSS software (statistical package for social studies) version 22.0 (IBM corporation ) for statistical analysis. The data was analyzed using chi square test and $p$ value less than 0.05 was considered statistically significant.

\section{RESULTS AND DISCUSSION}

The total sample size of this study was 2178 patients with the use of tobacco habits among them $87.8 \%$ of the patients were male and 12.17\% were females (Figure 1). Among three categories of habits which is smoking, smokeless tobacco and both smoking and smokeless tobacco habit; male had a higher rate with $66.21 \%, 15.89 \%$ and $5.74 \%$ respectively, females were commonly only involved in smokeless habits with a rate of $11.89 \%$ (Figure 2). Both males and females were mostly affected with generalised chronic gingivitis with $43.71 \%$ and $7.62 \%$. This association between gender and various periodontal disease was statistically significant (Figure 3).

Figure 4 shows the association between age and habits, the smoking as well as smokeless habit was common in all age groups although it was highest among the age group of 21$30 y r s$ with smoking habit being $20.66 \%$, smokeless tobacco habit being $8.22 \%$ and patients with both smokeless and smoking habit being $1.79 \%$. The age group 21-30years were mostly affected with generalised chronic gingivitis $(22.77 \%)$ and the age group 51-60years were mostly affected with generalised chronic periodontitis $(8.91 \%)$ as seen in Figure 5. With respect to association between periodontal diseases and habits from Figure 6, generalised chronic gingivitis was mostly seen in all three groups (31.36\%, $17.45 \%$ \& $2.53 \%$ ) followed by generalised chronic periodontitis $(20.06 \%, 4.41 \%$, $1.70 \%)$.

From this study it is seen that males $(87.8 \%)$ were commonly involved in tobacco consumption more than females(12.2\%) as seen in Figure 1, Association between gender and tobacco habits from Figure 2, shows that smoking was mostly seen in males $(66.2 \%)$ while in females it was very minimal. In the case of smokeless tobacco habit females had a rate of $11.89 \%$ and males $15.89 \%$. Males were commonly involved in using both smoking and smokeless tobacco (57.4\%). These results coincide with a study done by Rani et al. in 2003, as it shows that males had a higher rate of tobacco 
consumption than females in India [32]. It was also seen that both males and females were affected by generalised chronic gingivitis although males had a higher percentage among them with a rate of $43.71 \%$ as seen in Figure 3, these results were statistically significant. These results correlated with other studies [33, 34], stating that males were more periodontally affected than women among tobacco users.

In association of age with habit and periodontal disease, the results were statistically significant as seen in Figure 4 and Figure 5. In case of habits, there was a higher rate of tobacco use among the age group 21-30yrs in which $20.66 \%$ smoking, $8.22 \%$ smokeless tobacco and $1.79 \%$ had both smoking and smokeless tobacco habits. In case of periodontal diseases, generalised chronic gingivitis was at peak in 21-30yrs patients $(22.7 \%)$ while generalised chronic periodontitis was seen among the age group 51-60yrs (8.9\%). These results were in accordance with the findings of Bhandarkar GP et al [35] and Bains et al [36].

This study shows that generalised chronic gingivitis was the most common periodontal disease among all three groups with significantly higher rate among the smoking group $(31.36 \%)$ which is then followed by generalised chronic periodontitis among the three groups as seen in figure 6 . These results were statistically significant. Although these results were not in accordance with previous studies by gautam et al [37] and feldman et al [38], in which they reported smokers had less incidence of gingival bleeding. The possible finding of this in their study is the inhibitory effect of nicotine. The researchers believe that the effects of smoking on vascular status are caused by nicotine compounds. Nicotine due to stimulating the production of adrenaline and noradrenaline causes vasoconstriction and this leads to the decreasing of bleeding and exudates production [39]. It has been long said that there is a clear association between the periodontal status and systemic health of a patient often oral health care facilities serve as the primary contact points for the people in chronic conditions [40]. Dentists administering an efficient anti tobacco counselling could achieve 10\% $-15 \%$ quit rate in a year [41]. In this context dentists play an important role in improving the health status of the communities they are serving [42].

The present study is the first of its kind to assess periodontal health in patients using tobacco products in the Chennai population, with a large sample size. The limitations of the study is that periodontal parameters such 
as bleeding on probing, probing depth, size and the geographic area of coverage attachment loss and bone loss were not should be extended to at least most parts of evaluated. The study was geographically South India. Conducting a multicentered limited and predominantly consisted of the study with extended geographic area and South Indian population from chennai. To ascertain the results of this study and to wide range of population in future we can increase the level of significance, the sample obtain better results.

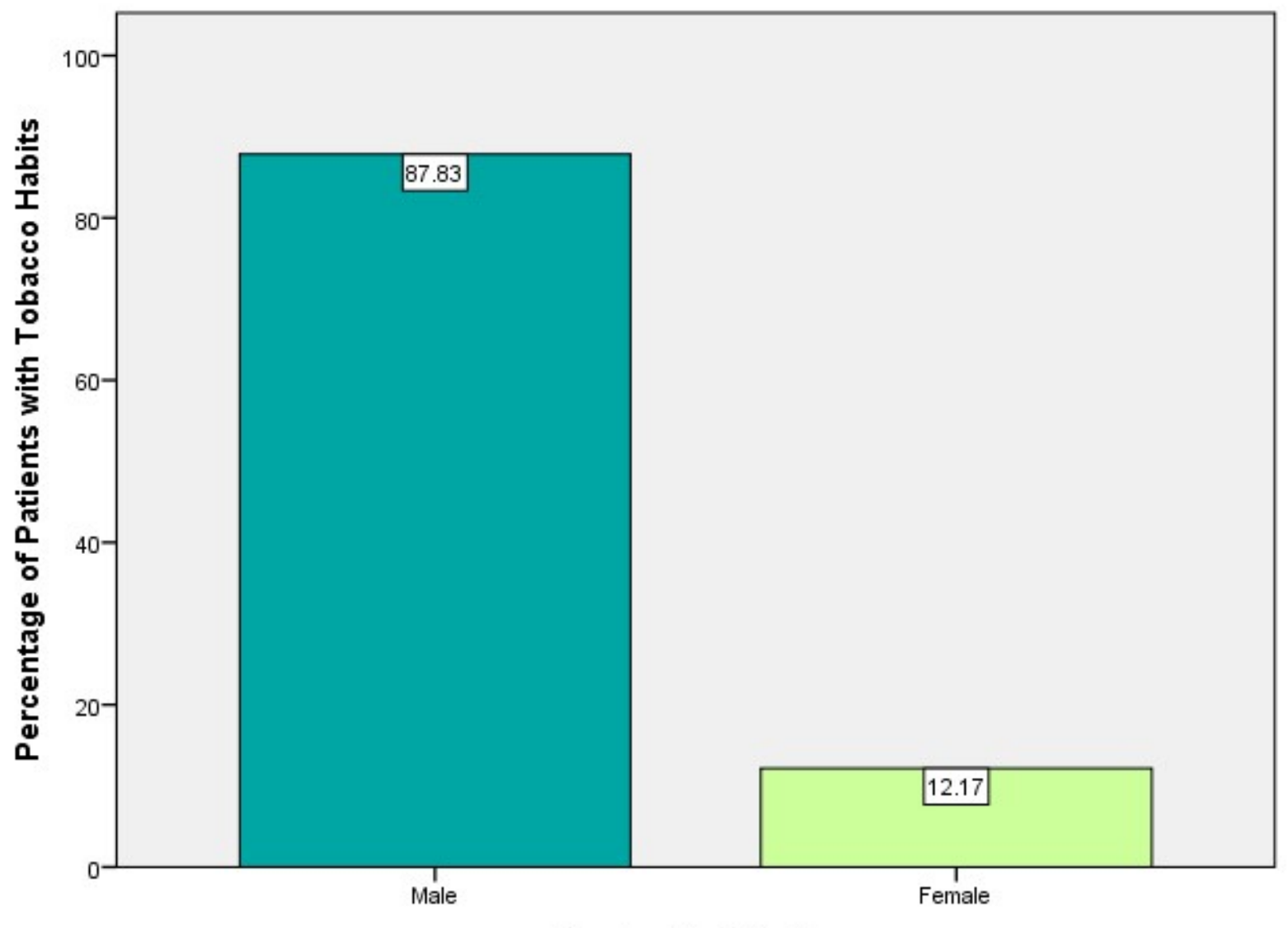

Gender Distribution

Figure 1: This bar graph represents the percentage of patients with tobacco habits based on gender distribution. $X$ axis represents the gender distribution and $Y$ axis represents the percentage of patients with tobacco habits. From this graph we can infer that Males(87.83\%) (Persian blue) were commonly more involved in using tobacco products than females(12.17\%) (Mint Green). 


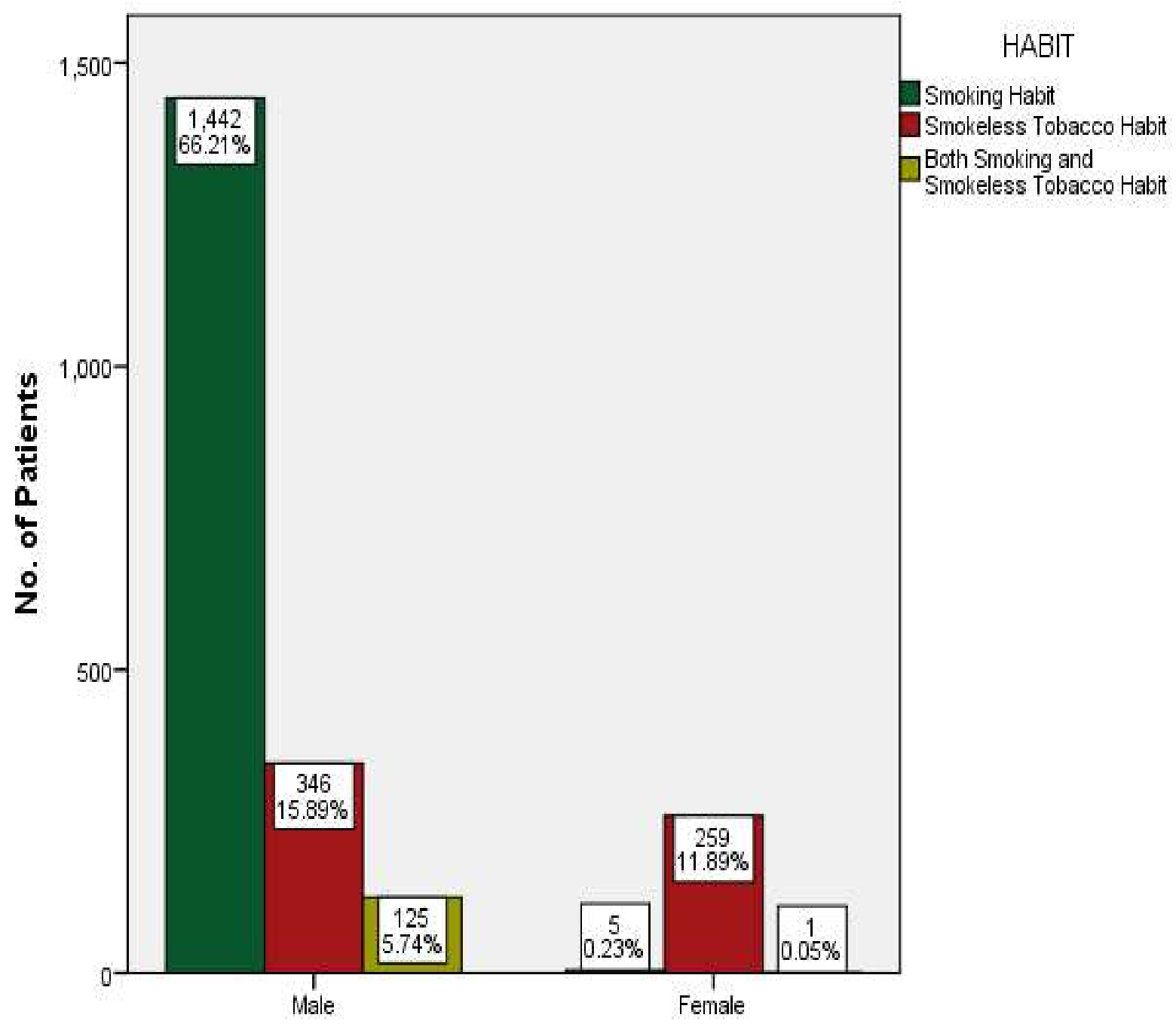

Gender Distribution

Figure 2: This bar graph represents the association between gender and the various tobacco habits. $X$ axis represents the Gender distribution and $Y$ axis represents the no of patients. From this bar graph we can infer that males were mostly involved in smoking habits $(66.21 \%)$ while among females, they were mostly involved in Smokeless tobacco habits(Brick

Red) with $11.89 \%$ and the rate of smoking and patients with both smoking and smokeless tobacco habits were very minimal. This association between gender and various habits was statistically significant, Chi square value $\mathbf{- 7 3 6 . 0 5 3}$ and $P$ value $=\mathbf{0 . 0 0 0}$ 


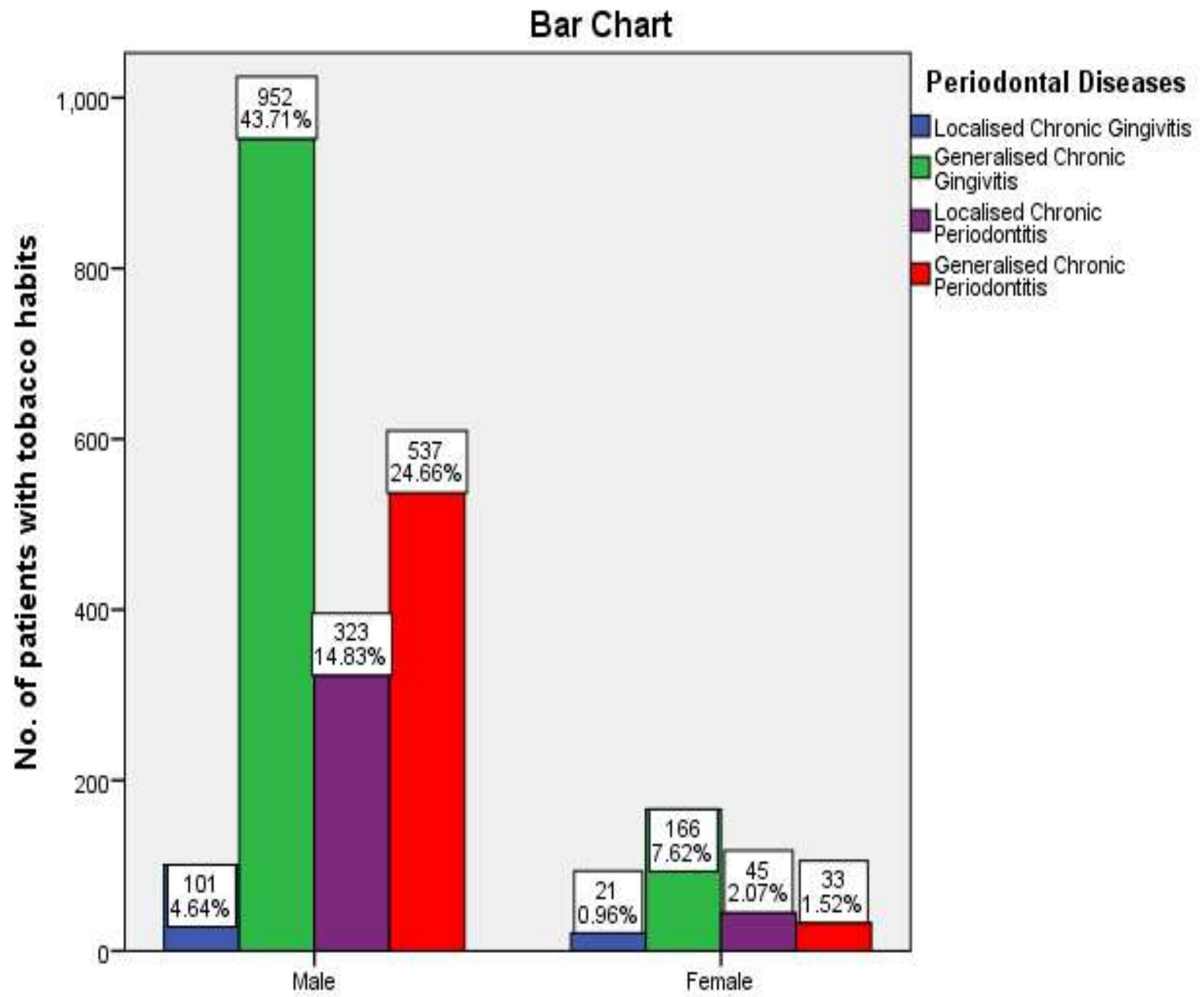

\section{Gender Distribution}

Figure 3: This bar graph represents the association between gender distribution and the various periodontal diseases among the patients. $X$ axis represents the Gender distribution and $Y$ axis represents the no of patients. Both males and females were mostly affected with generalised chronic gingivitis(Green) with $43.71 \%$ and $7.62 \%$. This association between gender and various periodontal disease was statistically significant, Chi square value $=\mathbf{3 2 . 1 2 1}$ and $P$ value $=.000$. 


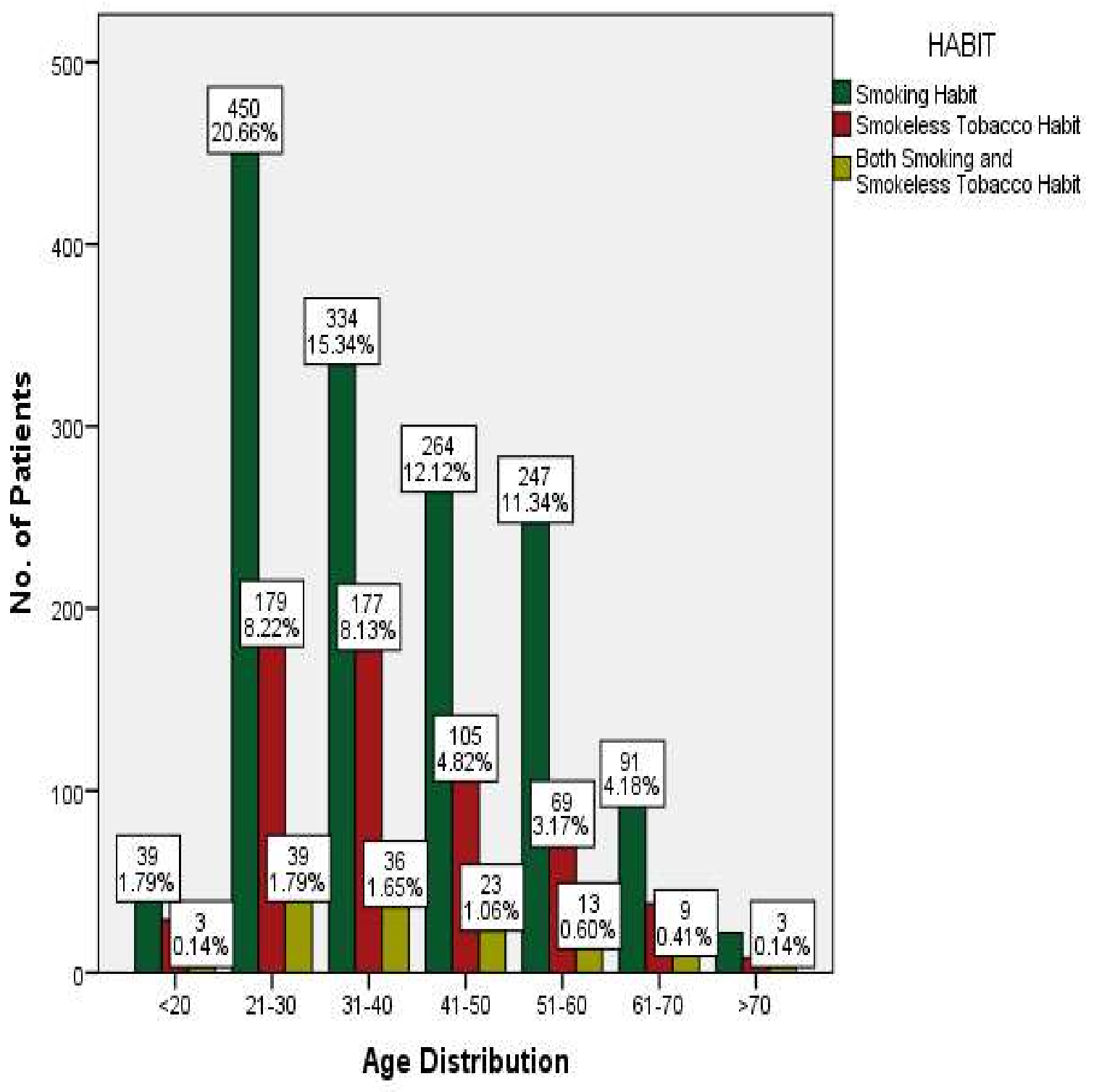

Figure 4: This bar graph represents the association between age distribution and the various periodontal diseases among the patients. $X$ axis represents the Age distribution and $Y$ axis represents the no of patients. From this bar graph we can infer that the age group 21-30years were mostly involved with tobacco habits; smoking(Jewel Green) being $20.66 \%$, smokeless tobacco(Brick Red) being $8.22 \%$ and patients with both smoking and smokeless tobacco habits(Olive Green) being $1.79 \%$. This association between age distribution and various tobacco habits was statistically significant, chi square value 25.706 and $P$ value $=0.012$. 


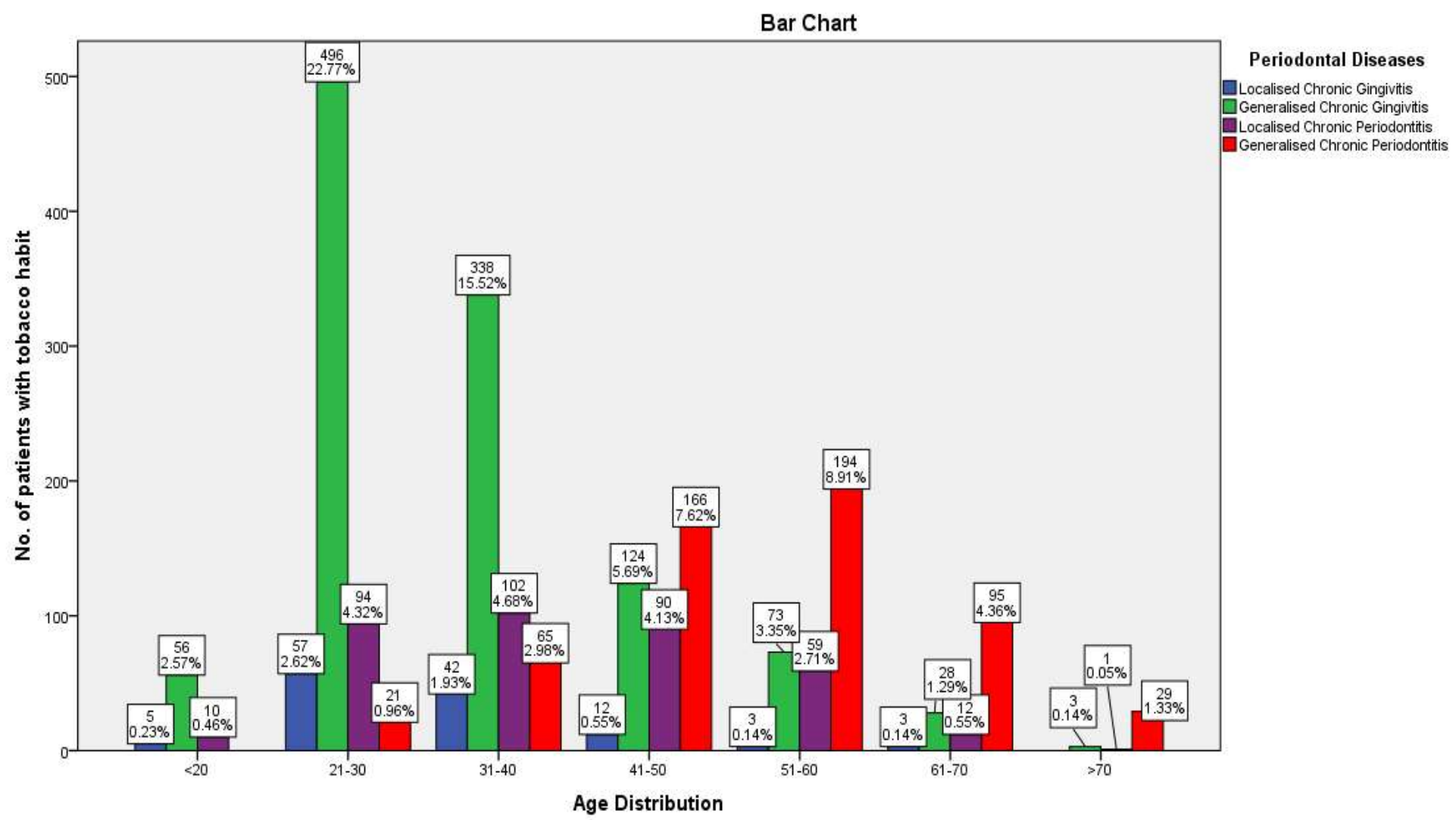

Figure 5: This bar graph represents the association between Age distribution and the various periodontal diseases among the patients. $\mathrm{X}$ axis represents the Age distribution and $\mathrm{Y}$ axis represents the no of patients. From this bar graph we can infer that the age group 21-30years were mostly affected with generalised chronic gingivitis(Green) $(22.77 \%)$ and the age group 51-60years were mostly affected with generalised chronic periodontitis(Red) $(8.91 \%)$. This association between age and various periodontal diseases was statistically significant, chi square value 786.343 and $p$ value $=0.000$. 


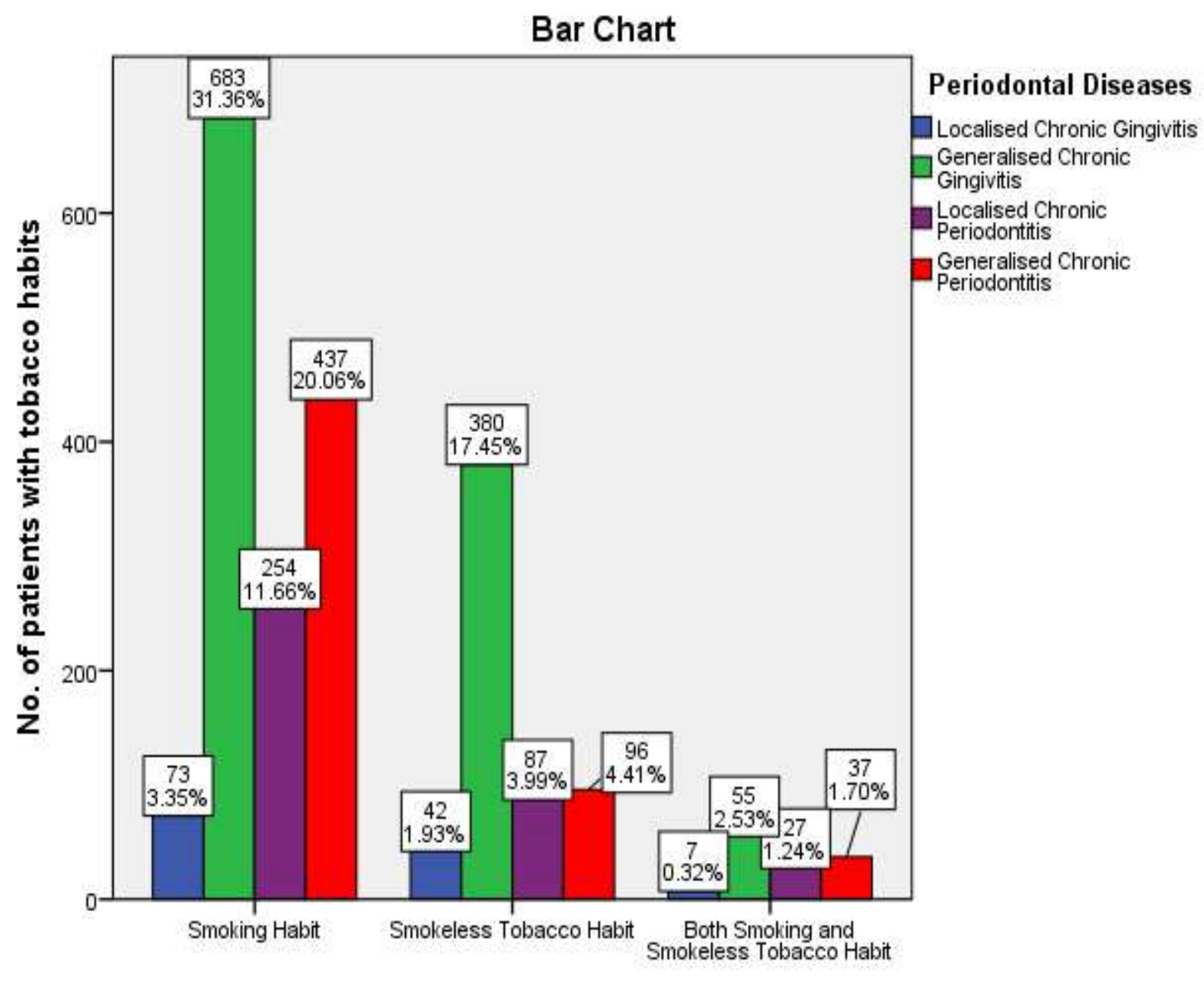

Various Tobacco Habits

Figure 6: This bar graph represents the association between various habits among the patients and the various periodontal diseases among the patients. $X$ axis represents the various habits among the patients and $Y$ axis represents the number of patients. From this bar graph we can infer that generalised chronic gingivitis(Green) was mostly seen in all three groups $31.36 \%, 17.45 \%$ \& $2.53 \%$ followed by generalised chronic periodontitis(Red) $20.06 \%, 4.41 \%, 1.70 \%$. This association between various tobacco habits and various periodontal disease was statistically significant, chi square value 62.705 and $p$ value $=0.000$.

\section{CONCLUSION}

Within the limit of the study, we can conclude that the tobacco use has direct effect on the periodontium as most commonly the patients were affected with generalised chronic gingivitis followed by generalised chronic periodontitis with males mostly affected and among the age of 21$30 \mathrm{yrs}$. There is a need for further longitudinal studies in a large number of populations to assess the relationship of smoking and smokeless tobacco consumption with periodontal disease. 


\section{Acknowledgement}

The authors are thankful to Saveetha Dental College for providing a platform to express our knowledge

\section{Conflict of interest}

The authors declare no conflict of interest

\section{REFERENCES}

[1] Yaragani A, VR Sushuma K, Guduri V, Manikanta Kumar S, Vishnubhotla G, Kandikatla $\mathrm{P}$, et al. The influence of tobacco consumption on periodontal health: A stratified analysis based on type of tobacco use. Journal of Family Medicine and Primary Care. 2020 Apr 1;9(4):2061.

[2] GATS 2 Global Adult Tobacco Survey [Internet]. Available from: https://www.who.int/tobacco/surveill ance/survey/gats/GATS_India_201617_FactSheet.pdf?ua $=1$

[3] Nci US, Others. WHO. The Economics of Tobacco and Tobacco Control. National Cancer Institute Tobacco Control Monograph 21. NIH Publication; 2016.

[4] Products $\mathrm{C}$ on TPHI of RTMAFPT, Committee on the Public Health Implications of Raising the Minimum Age for Purchasing Tobacco Products, Board on Population Health and Public Health Practice, Institute of Medicine. Public Health Implications of Raising the Minimum Age of Legal Access to Tobacco Products [Internet]. 2015. Available from:

http://dx.doi.org/10.17226/18997

[5] Leite FRM, Nascimento GG, Scheutz F, López R. Effect of Smoking on Periodontitis: A Systematic Review and Meta-regression [Internet]. Vol. 54, American Journal of Preventive Medicine. 2018. p. 831-41. Available from:

http://dx.doi.org/10.1016/j.amepre.20 18.02.014

[6] Johnson NW. The role of the dental team in tobacco cessation. Eur J Dent Educ. 2004 Feb;8 Suppl 4:18-24.

[7] Newman MG, Takei H, Klokkevold PR, Carranza FA. Carranza's Clinical Periodontology. Elsevier Health Sciences; 2011.872 p.

[8] Hyman JJ, Reid BC. Epidemiologic risk factors for periodontal attachment loss among adults in the United States. J Clin Periodontol. 2003 Mar;30(3):230-7.

[9] Tomar SL, Asma S. Smokingattributable periodontitis in the United States: findings from 
NHANES III. J Periodontol.

2000;71(5):743-51.

[10] Villar CC, de Lima AF. Smoking influences on the thickness of marginal gingival epithelium. Pesqui Odontol Bras. 2003 Jan;17(1):41-5.

[11] de Oliveira Semenzati G, de Souza Salgado B, Rocha NS, Michelin Matheus SM, de Carvalho LR, Garcia Martins RH. Histological and immunohistochemical study of the expression of p53 and ki-67 proteins in the mucosa of the tongue, pharynx and larynx of rats exposed to cigarette smoke. Inhal Toxicol. 2012;24(11):723-31.

[12] Sanghvi LD, Rao KCM, Khanolkar VR. Smoking and Chewing of Tobacco in Relation to Cancer of the Upper Alimentary Tract [Internet]. Vol. 1, BMJ. 1955. p. 1111-4. Available from: http://dx.doi.org/10.1136/bmj.1.492

\subsection{1}

[13] Axéll T. A prevalence study of oral mucosal lesions in an adult Swedish population. Odontol Revy Suppl. 1976;36:1-103.

[14] Frithiof L, Anneroth G, Lasson U, Sederholm C. The snuff-induced lesion. A clinical and morphological study of a Swedish material. Acta Odontol Scand. 1983;41(1):53-64.

[15] Haber J, Wattles J, Crowley M, Mandell R, Joshipura K, Kent RL. Evidence for cigarette smoking as a major risk factor for periodontitis. J Periodontol. 1993 Jan;64(1):16-23.

[16] Amarasinghe HK, Usgodaarachchi US, Johnson NW, Lalloo R, Warnakulasuriya S. Betel-quid chewing with or without tobacco is a major risk factor for oral potentially malignant disorders in Sri Lanka: a case-control study. Oral Oncol. 2010 Apr;46(4):297-301.

[17] Varghese SS, Thomas H, Jayakumar ND, Sankari M, Lakshmanan R. Estimation of salivary tumor necrosis factor-alpha in chronic and aggressive periodontitis patients. Contemp Clin Dent. 2015 Sep;6(Suppl 1):S152-6.

[18] Priyanka S, Kaarthikeyan G, Nadathur JD, Mohanraj A, Kavarthapu A. Detection of cytomegalovirus, Epstein-Barr virus, and Torque Teno virus in subgingival and atheromatous plaques of cardiac patients with chronic periodontitis. J Indian Soc 
Periodontol. 2017 Nov;21(6):45660.

[19] Kavarthapu A, Thamaraiselvan M. Assessing the variation in course and position of inferior alveolar nerve among south Indian population: A cone beam computed tomographic study. Indian J Dent Res. 2018 Jul;29(4):405-9.

[20] Thamaraiselvan M, Elavarasu S, Thangakumaran S, Gadagi JS, Arthie T. Comparative clinical evaluation of coronally advanced flap with or without platelet rich fibrin membrane in the treatment of isolated gingival recession. J Indian Soc Periodontol. 2015 Jan;19(1):6671.

[21] Panda S, Jayakumar ND, Sankari M, Varghese S, Kumar D. Platelet rich fibrin and xenograft in treatment of intrabony defect [Internet]. Vol. 5, Contemporary Clinical Dentistry. 2014. p. 550. Available from: http://dx.doi.org/10.4103/0976$237 \mathrm{x} .142830$

[22] Ravi S, Malaiappan S, Varghese S, Jayakumar ND, Prakasam G. Additive Effect of Plasma Rich in Growth Factors With Guided Tissue Regeneration in Treatment of
Intrabony Defects in Patients With Chronic Periodontitis: A SplitMouth Randomized Controlled Clinical Trial [Internet]. Vol. 88, Journal of Periodontology. 2017. p. 839-45. Available from: http://dx.doi.org/10.1902/jop.2017.1 60824

[23] Ramesh A, Vellayappan R, Ravi S, Gurumoorthy K. Esthetic lip repositioning: A cosmetic approach for correction of gummy smile - A case series [Internet]. Vol. 23, Journal of Indian Society of Periodontology. 2019. p. 290. Available from: http://dx.doi.org/10.4103/jisp.jisp_5 48_18

[24] Ramamurthy J, Mg V. Comparison Of Effect Of Hiora Mouthwash Versus Chlorhexidine Mouthwash In Gingivitis Patients: A Clinical Trial. Asian J Pharm Clin Res. 2018;11(7):84-8.

[25] Ramesh A, Varghese S, Doraiswamy J, Malaiappan S. Herbs as an antioxidant arsenal for periodontal diseases [Internet]. Vol. 5, Journal of Intercultural Ethnopharmacology. 2016. p. 92. Available from: 
http://dx.doi.org/10.5455/jice.20160 122065556

[26] Khalid W, Varghese SS, Sankari M, Jayakumar ND. Comparison of Serum Levels of Endothelin-1 in Chronic Periodontitis Patients Before and After Treatment. J Clin Diagn Res. 2017 Apr;11(4):ZC7881.

[27] Ramesh A, Ravi S, Kaarthikeyan G. Comprehensive rehabilitation using dental implants in generalized aggressive periodontitis. J Indian Soc Periodontol. 2017 Mar;21(2):160-3.

[28] Avinash K, Malaippan S, Dooraiswamy JN. Methods of Isolation and Characterization of Stem Cells from Different Regions of Oral Cavity Using Markers: A Systematic Review. Int $\mathrm{J}$ Stem Cells. 2017 May 30;10(1):12-20.

[29] Ramesh A, Varghese SS, Jayakumar ND, Malaiappan S. Chronic obstructive pulmonary disease and periodontitis--unwinding their linking mechanisms. J Oral Biosci. 2016;58(1):23-6.

[30] Mootha A, Malaiappan S, Jayakumar ND, Varghese SS, Thomas JT. The Effect of
Periodontitis on Expression of Interleukin-21: A Systematic Review [Internet]. Vol. 2016, International Journal of Inflammation. 2016. p. 1-8. Available from: http://dx.doi.org/10.1155/2016/3507 503

[31] Khalid W, Vargheese SS, Lakshmanan R, Sankari M, Jayakumar ND. Role of endothelin1 in periodontal diseases: A structured review. Indian J Dent Res. 2016 May;27(3):323-33.

[32] Rani M, Bonu S, Jha P, Nguyen SN, Jamjoum L. Tobacco use in India: prevalence and predictors of smoking and chewing in a national cross sectional household survey. Tob Control. 2003 Dec;12(4):e4.

[33] Ragghianti MS, Greghi SLA, Lauris JRP, Sant'ana ACP, Passanezi E. Influence of age, sex, plaque and smoking on periodontal conditions in a population from Bauru, Brazil. J Appl Oral Sci. 2004 Dec;12(4):2739.

[34] Bansal M, Mittal N, Singh TB. Assessment of the prevalence of periodontal diseases and treatment needs: A hospital-based study. J 
Indian Soc Periodontol. 2015 Mar;19(2):211-5.

[35] Bhandarkar GP, Shetty KV, Others. Correlation of periodontal parameters to various types of smokeless tobacco in tobacco pouch keratosis patients: A cross-sectional study. 2020; Available from: http://www.cancerjournal.net/prepri ntarticle.asp?id $=268780$

[36] Bains V, Rizvi I, Singh GP, Gupta $\mathrm{V}$. Influence of smokeless tobacco on periodontal health status in local population of North India: A crosssectional study [Internet]. Vol. 8, Dental Research Journal. 2011. p. 211. Available from: http://dx.doi.org/10.4103/17353327.86045

[37] Gautam DK, Gupta SC, Kotwal B, Jindal V, Tuli A, Thakur R. Effect of cigarette smoking on the periodontal health status: A comparative, cross sectional study [Internet]. Vol. 15, Journal of Indian Society of Periodontology. 2011. p.
383.

Available from:

http://dx.doi.org/10.4103/0972-

124x.92575

[38] Feldman RS, Bravacos JS, Rose CL. Association between smoking different tobacco products and periodontal disease indexes. $\mathrm{J}$ Periodontol. 1983 Aug;54(8):481-7. [39] Sreedevi M, Ramesh A, Dwarakanath C. Periodontal status in smokers and nonsmokers: a clinical, microbiological, and histopathological study. Int J Dent. 2012 Feb 14;2012:571590.

[40] Hummel J, Phillips KE, Holt B, Hayes C. Oral health: an essential component of primary care. Seattle: Qualis Health. 2015;

[41] Warnakulasuriya S. Effectiveness of tobacco counseling in the dental office. J Dent Educ. 2002 Sep;66(9):1079-87.

[42] Zhang Y, He J, He B, Huang R, Li M. Effect of tobacco on periodontal disease and oral cancer. Tob Induc Dis. 2019 May 9;17:40. 